\title{
Cervical Rib: Dept of Neurosurgery Khoula Hospital Muscat Oman Experience: A Critical Analysis
}

\author{
Ali Al Mashani, Neeraj Salhotra*, Azmat Ali, Munthir Al Zabin, Salim Al Abri, \\ Arshad Kabir Khan, Ahmed Al Risi \\ Department of Neurosurgery, Khoula Hospital Muscat, Oman \\ *Corresponding author: neersal@hotmail.com
}

\begin{abstract}
An extra rib arising from seventh cervical vertebra is termed as cervical rib. The condition is a congenital anomaly. Thoracic outlet syndrome is the common presentation. [1] Resection of the rib alleviate the symptoms. We present here our experience of cervical rib resection and a critical analysis of condition with literature review.
\end{abstract}

\section{Keywords: Cervical rib}

Cite This Article: Ali Al Mashani, Neeraj Salhotra, Azmat Ali, Munthir Al Zabin, Salim Al Abri, Arshad Kabir Khan, and Ahmed Al Risi, "Cervical Rib: Dept of Neurosurgery Khoula Hospital Muscat Oman Experience: A Critical Analysis.” American Journal of Medical Case Reports, vol. 5, no. 2 (2017): 43-47. doi: 10.12691/ajmcr-5-2-6.

\section{Introduction}

Cervical rib is known to have an incidence of .6\% in the population. It can be either bilateral or only on one side. Thoracic outlet syndrome is the common presentation. However a major population cervical rib is detected incidentally and patients are asymptomatic. [1] Size and shape of the cervical rib also has different anatomic profile. Persistent ossification of the C7 lateral costal cartilage is attributed to the formation of cervical rib. Hence elongation of transverse process or a complete cervical rib or fusion to the $1 \mathrm{st}$ rib are various anomalies which are encountered. Inferolateral projection in comparison to the normal anterolateral projection of thoracic transverse process is the differentiation for the cervical rib. Brachial plexus compression or subclavian artery compression by cervical rib leads to positive Adson's test on examination. Excision of the rib via various approaches, superaclavicular, trans axillary or inferaclavicular is generally practiced [4].

\section{Material and Methods}

We present series of 8 patients operated by two consultants in our department. All patients presented with symptoms of thoracic outlet syndrome of varying intensity. All patients were investigated thoroughly with a $\mathrm{x}$ ray chest, CT scan, MRI cervical spine and EMG /NCV studies to rule out the associated or other conditions. After confirming the cervical rib, hypertrophied transverse process or a band from transverse process compressing the neurovascular structures causing thoracic outlet syndrome treatment option was planned and discussed with the patient.
Superclavicular approach via small incision in the scalene triangle was the choice of operating consultant. After retracting the clavicular head of the sternoceidomastoid muscle the scalene anterior muscle with phrenic nerve crossing it from lateral to medial size was appreciated. The Subclavian vein was seen anterior to scalene anterior muscle and subclavian artery and brachial plexus were seen between the scalene anterior and medial muscle. Cervical rib was seen here causing the compression of neurovascular bundle. Post stenotic dilatation of subclavian artery was not noticed in our series of patients. After careful retraction of neurovascular bundles the excision of cervical rib was performed subperiosteally till C7 vertebra removing all compressing elements on scalene triangle neurovasdcular structures. Pleural injury was carefully avoided. Haemostasis was achieved adequately and closure of wound was done in a conventional way.

\section{Results}

The patients are tabulated as per Figure 5. Age of our patients ranged from 16 yrs to 46 yrs. Male female ratio was 2: 6. Presentation was neck pain with cervical radiculopathy in 6 patients and in two had associated hand pain and numbness too. One patient required later carpal tunnel decompression too. Adson test was positive in 4 of our patients. Investigations done were Xray, CT scan, MRI cervical spine and EMG/NCV studies in all of our patients. MRI cervical spine was done to rule out any associated disc disease. In two patients rib was bilateral. One was symptomatic only on one side other had on both sides and required two surgeries. Surgical approach in all patients was superaclavicular. Complications included in one patient persistence of symptoms and required decompression of carpel tunnel syndrome too. Other all 
patients improved in the symptoms. Patients are all being followed up in outpatient clinic.

Table 1.

\begin{tabular}{|c|c|c|c|c|c|c|c|c|}
\hline S.No & $\begin{array}{l}\text { Hospital } \\
\text { ID No. }\end{array}$ & Sex & Age & Symptoms & Investigation & Date of surgery & Complications & Follow up \\
\hline 1 & 480171 & Female & 36 yrs & $\begin{array}{l}\text { Bilateral hand } \\
\text { and neck pain }\end{array}$ & $\begin{array}{l}\text { X ray, CT, MRI } \\
\text { and } E M G / N C V\end{array}$ & $\begin{array}{l}\text { 5/4/2006 left, } \\
\text { 14/5/2006 right }\end{array}$ & nil & $\begin{array}{c}1 \mathrm{yr} \\
\text { Satisfactory }\end{array}$ \\
\hline 2 & 492761 & Female & 39 yrs & $\begin{array}{l}\text { Pain left side } \\
\text { neck and hand }\end{array}$ & $\begin{array}{l}\text { X ray, CT, MRI } \\
\text { and EMG/NCV }\end{array}$ & 7/6/2006 & nil & $\begin{array}{c}3 \text { yrs } \\
\text { Satisfactory }\end{array}$ \\
\hline 3 & 351660 & Female & $37 \mathrm{yrs}$ & $\begin{array}{l}\text { Left hand } \\
\text { numbness }\end{array}$ & $\begin{array}{l}\text { X ray, CT, MRI } \\
\text { and EMG/NCV }\end{array}$ & $18 / 9 / 2006$ & $\begin{array}{l}\text { Was symptomatic } \\
\text { required carpal tunnel } \\
\text { decompression too }\end{array}$ & $\begin{array}{c}\text { 7yrs } \\
\text { satisfactory }\end{array}$ \\
\hline 4 & 377249 & Female & 38 yrs & $\begin{array}{c}\text { Pain and } \\
\text { numbness in } \\
\text { left sided limbs }\end{array}$ & $\begin{array}{l}\mathrm{X} \text { ray, } \mathrm{CT}, \mathrm{MRI} \\
\text { and } \mathrm{EMG} / \mathrm{NCV}\end{array}$ & $1 / 11 / 2006$ & nil & 7 yrs satisfactory \\
\hline 5 & 66654 & Female & 58 yrs & $\begin{array}{l}\text { Left sided pain } \\
\text { and numbness }\end{array}$ & $\begin{array}{l}\text { X ray, CT, MRI } \\
\text { and EMG/NCV }\end{array}$ & $22 / 6 / 2009$ & nil & $\begin{array}{c}1 \mathrm{yr} \\
\text { Satisfactory }\end{array}$ \\
\hline 6 & 697916 & Male & 45 yrs & $\begin{array}{l}\text { Left sided } \\
\text { Neck pain }\end{array}$ & $\begin{array}{l}\text { X ray, CT, MRI } \\
\text { and EMG/NCV }\end{array}$ & 20/11/2011 & nil & Lost to follow up \\
\hline 7 & 789762 & Female & 46 yrs & $\begin{array}{l}\text { Right sided } \\
\text { neck pain and } \\
\text { numbness }\end{array}$ & $\begin{array}{l}\mathrm{X} \text { ray, } \mathrm{CT}, \mathrm{MRI} \\
\text { and } \mathrm{EMG} / \mathrm{NCV}\end{array}$ & $20 / 1 / 2014$ & Nil & $\begin{array}{l}\text { One follow up in OPD } \\
\text { after } 2 \text { months } \\
\text { satisfactory }\end{array}$ \\
\hline 8 & 508752 & Male & $16 \mathrm{yrs}$ & $\begin{array}{l}\text { Left sided neck } \\
\text { pain and } \\
\text { numbness }\end{array}$ & & 23/1/2017 & nil & $\begin{array}{l}\text { Immidiate post op } \\
\text { period uneventful awaits } \\
\text { follow up in OPD }\end{array}$ \\
\hline
\end{tabular}

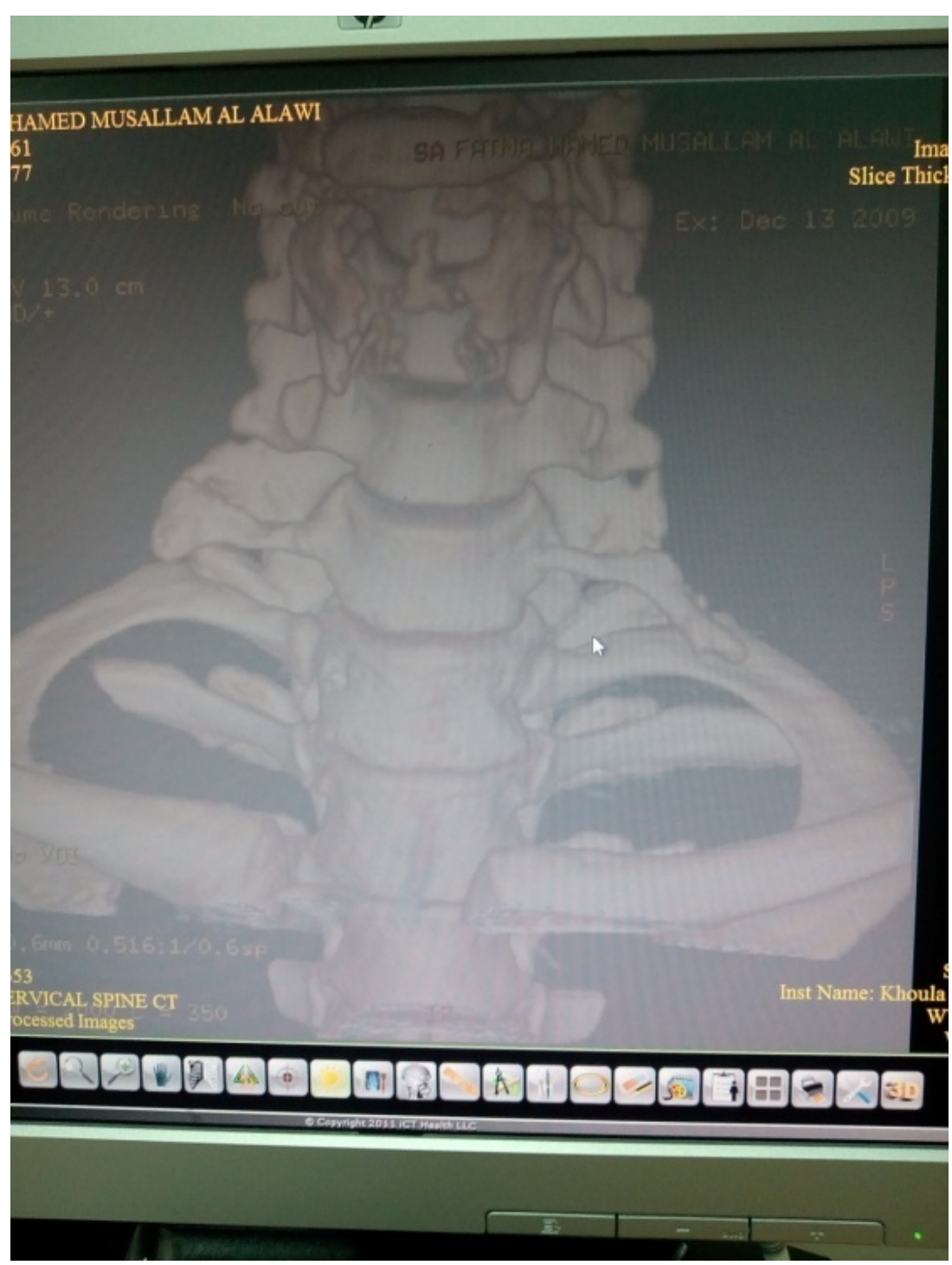

Figure 1. CT scan of Patient no 2 showing left sided cervical rib 


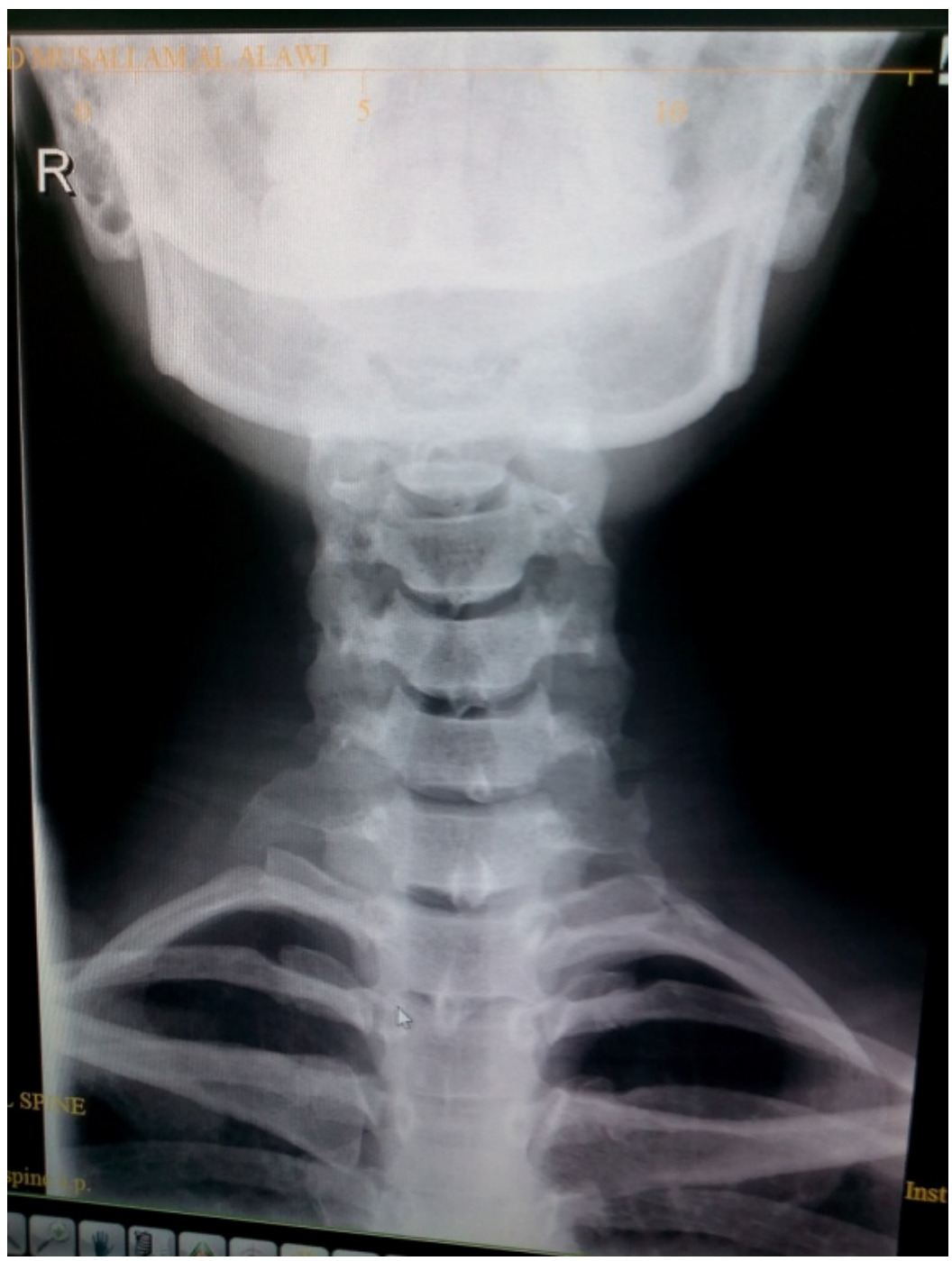

Figure 2. $\mathrm{X}$ ray neck showing right sided cervical rib of patient no 7

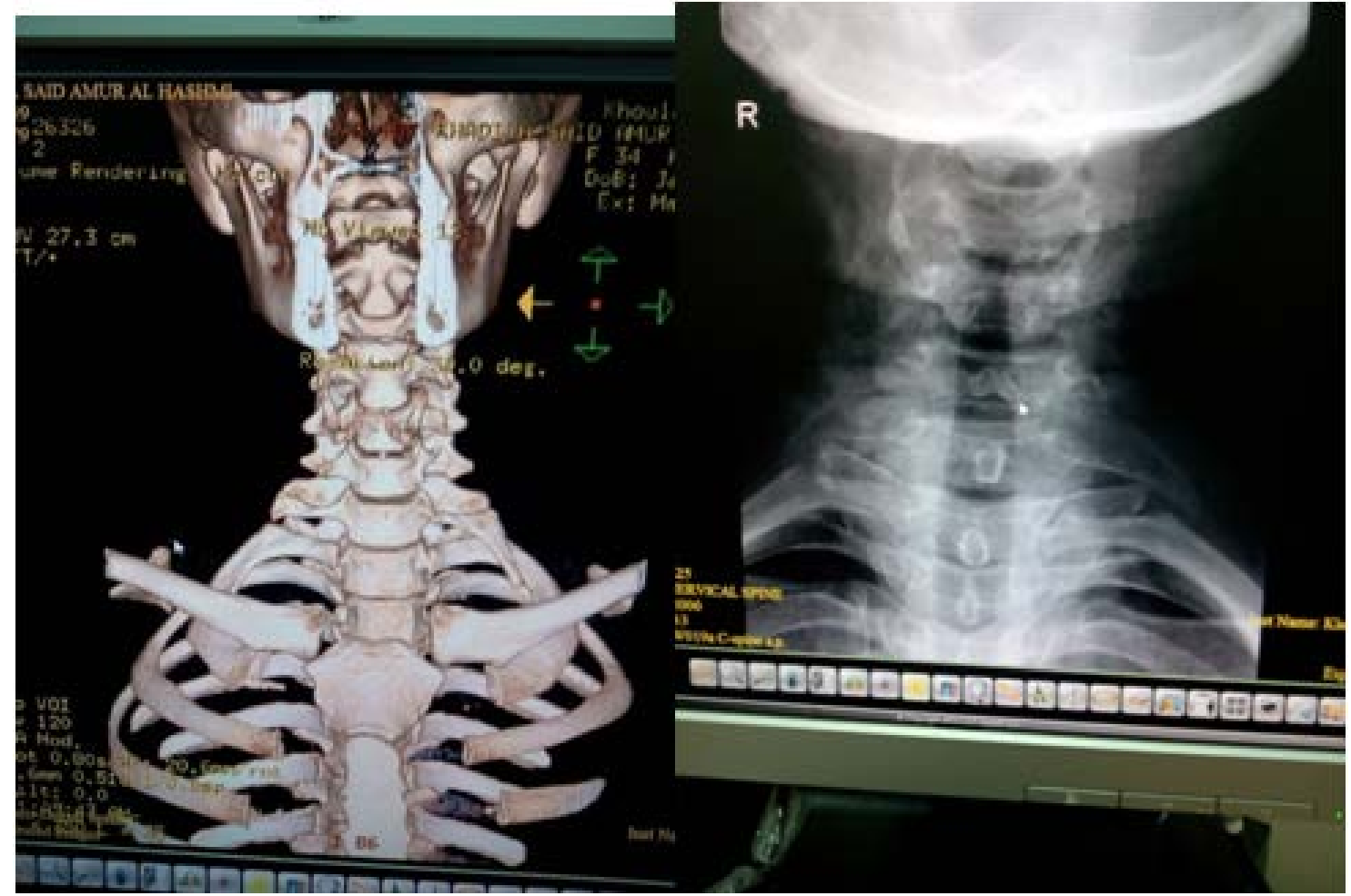

Figure 3. CT and X ray of patient no 4 showing left sided cervical ribs 


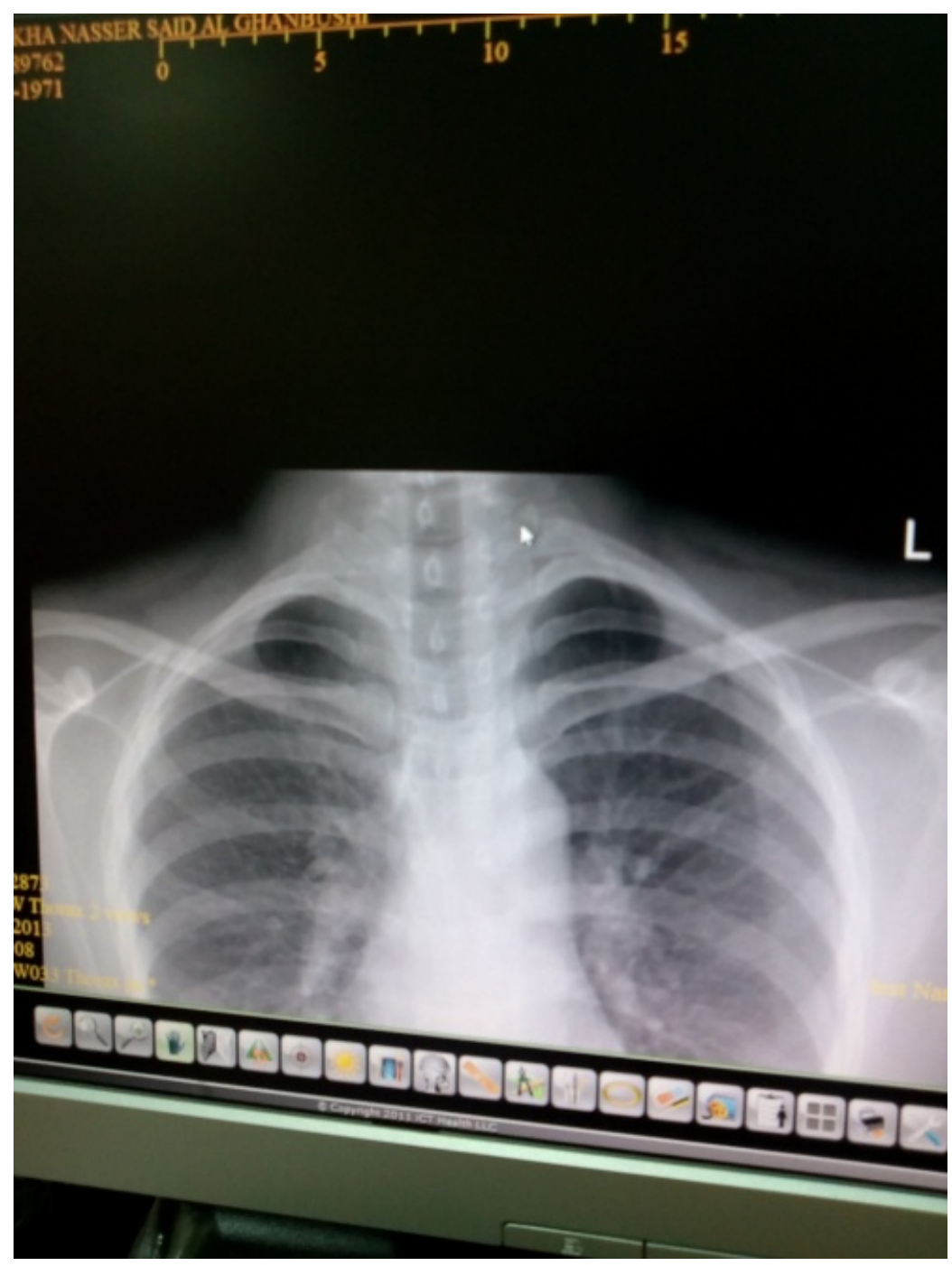

Figure 4. $\mathrm{X}$ ray showing cervical rib of patient no 8

\section{Discussion}

As reviewed in the literature cervical rib is not an uncommon entity but mostly managed by thoracic or vascular surgeons. As we further review the literature Ferrante MA and Ferrante ND in 2016 reported the thoracic outlet syndrome caused by cervical rib into various categories viz arterial, venous, neurovascular and disputed thoracic outlet syndromes categories and their management thereof. Cervicoscapular pain has to be studied carefully to be distinguished from true thoracic outlet syndrome by carefully seeing anatomy, neurophysiology, electromagnetic correlations and underlying pathology. [1] Buyukkaya A Buyukkaya R in 2015 reported incidences where a cervical rib was mimicking a superaclavicular mass. [2] Ist rib itself or lesions thereof can present as TOS as reported by Kargar S et al in 2013 who reported a case of osteoid osteoma of the 1 st rib and case presented as thoracic outlet syndrome. [3] In 2009 White PW et al discussed in detail the cervical rib causing the arterial type of TOS with subclavian artery compression and etiology, pathophysiology, diagnostic and treatment plans were discussed. [4] In 1983 Neveu P etal described their 15 cases of cervical ribs causing vartious set of pathophysiologhies and role of ultrasound and computed angiography as useful tool in the management. [5] In 2011
Rivera-Vega A reported a case of bilateral cervical rib in an adolescent with fibrotendimous band being the reason for TOS and atrophy of hand muscles along with other neurogenic presentation treated by surgical excision of the rib with band on symptomatic side. [6] In Our case series youngest patient being matching this case report and establishing the treatment standards. In 2006 Hug U et al further emphasized patients presenting with thenar muscles hypotrophy and on investigations reveled cervical rib, enlarged C7 transverse process or a fibrotendinous band as a causative feature and surgical resection gave encouraging result [7].

To conclude our study further emphasised the TOS caused by cervical rib as a challenging condition. Thorough investigation with EMG/NCV, CT / X ray and MRI cervical spine to rule out associated cervical radiculopathy being the standard array of investigation prior to superaclavicular approach for excision of the cervical rib. Our small group owing to small population of country had negligible complications and good outcome.

\section{References}

[1] Ferrante MA, Ferrante ND. The thoracic outlet syndromes: Part 2. The Arterial, Venous, Neurovascular, and Disputed Thoracic Outlet Syndromes. Muscle Nerve 2016 Dec 22. 
[2] Buyukkaya A Buyukkaya R Ozel MA Erdogmus B Cervical rib mimicking supraclavicular mass. Joint, bone, spine: revue du rhumatisme 82:6 2015 Dec pg 464.

[3] Kargar S Arefanian S Ghasemi A Binesh F Heiranizadeh N. Osteoid osteoma of the rib presenting as thoracic outlet syndrome. The Annals of thoracic surgery 96:6 2013 Dec pg 2221-3.

[4] White PW Fox CJ Feuerstein IM. Cervical rib causing arterial thoracic outlet syndrome. Journal of the American College of Surgeons 209:1 2009 Jul pg 148-9.

[5] Abet D, Neveu P Ringot PL Burnay J Vermynck JP Brié A Pietri J. Vascular complications of cervical ribs. Apropos of 15 cases. Journal des maladies vasculaires 8:2 1983 pg 179-82.
[6] Rivera-Vega A Peguero L Colon E Saavedra FM Sosa I Ramos E. Fibrotendinous band causing neurogenic Thoracic Outlet Syndrome in adolescent with bilateral cervical ribs. Journal of pediatric rehabilitation medicine 4:2 $2011 \mathrm{pg}$ 149-54.

[7] Hug U Jung FJ Guggenheim M Wedler V Burg D Künzi W. "True neurologic thoracic outlet syndrome" -- anatomical features and electrophysiological long-term follow-up of lateral thenar atrophy. Handchirurgie, Mikrochirurgie, plastische Chirurgie: Organ der Deutschsprachigen Arbeitsgemeinschaft für Handchirurgie: Organ der Deutschsprachigen Arbeitsgemeinschaft für Mikrochirurgie der Peripheren Nerven und Gefässe: Organ der Vereinigung der Deutschen Plastischen Chirurgen 38:1 2006 Feb pg 42-5. 